\title{
Comunicación y estética-ética: el caso del monocultivo de la caña de azúcar
}

Germán Ayala Osorio

Universidad Autónoma de Occidente, Colombia 


\section{Comunicación y estética-ética: el caso del monocultivo de la caña de azúcar ${ }^{\star}$}

Resumen: en este artículo, se discurre alrededor de la comunicación, la estética-ética y la sostenibilidad como campos de saber y disciplinas y las hace confluir en el monocultivo de la caña de azúcar, asumido como un fenómeno estético-ambiental. Se proponen enunciados categoriales con los que se busca avanzar en el complejo análisis de una realidad agroindustrial sostenida en un orden simbólico y cultural específico, que traspasa los límites de la señalada práctica agrícola que debe y puede ser mirada y analizada desde la perspectiva del pensamiento ambiental complejo. Además, se exponen tres acápites transversalmente conectados por las dimensiones estética, ética, comunicativa y ambiental. En un primer momento, se da cuenta de lo que se entiende por comunicación y sus conexiones disciplinares. En un segundo momento se alude al objeto de la reflexión: el monocultivo de la caña de azúcar. En un tercer estadio, se abordan los temas de la sostenibilidad y la estética-ética, para intentar 'atrapar', con fines comprensivos, el monocultivo de la caña de azúcar.

Palabras clave: comunicación, monocultivo de la caña de azúcar, estética-ética, comunicación política, ecosistemas, naturaleza.

\section{Communication and aesthetics-ethics: the case of monoculture of sugarcane}

Abstract: in this article, it is discussed around communication, aesthetics-ethics and sustainability as fields of knowledge and disciplines and brings them together in the monoculture of sugarcane, assumed as an aesthetic-environmental phenomenon. It proposes categorical statements with which he seeks to advance in the complex analysis of an agro-industrial reality sustained in a specific symbolic and cultural order, which goes beyond the limits of the indicated agricultural practice that should and can be looked at and analyzed from the perspective of environmental thinking complex. Also, it presents three sections transversely connected by the aesthetic, ethical, communicative and environmental dimensions. At first, it gives an account of what he means by communication and his disciplinary connections. In a second moment, alludes to the object of reflection: the monoculture of sugar cane. In a third stage, the topics of sustainability and aesthetics-ethics are addressed, to try to 'catch', with comprehensive aims, the monoculture of sugarcane.

Keywords: communication, monoculture of sugarcane, aesthetics-ethics, political communication, ecosystems, nature.

Fecha de recepción: 29 de noviembre de 2018

Fecha de aceptación: 8 de mayo de 2019

Forma de citar (APA): Ayala-Osorio, G. (2020). Comunicación y estética-ética: el caso del monocultivo de la caña de azúcar. Revista Filosofía UIS, 19(1), DOI: 10.18273/revfil.v19n1-2020004

Forma de citar (Harvard): Ayala-Osorio, G. (2020). Comunicación y estética-ética: el caso del monocultivo de la caña de azúcar. Revista Filosofía UIS, 19(1), 263-284.

Germán Ayala Osorio: colombiano. Magíster en Estudios Políticos. Profesor Asociado I de la Universidad Autónoma de Occidente (Cali, Colombia). Candidato a Doctor en Regiones Sostenibles.

ORCID iD: orcid.org/0000-0001-6388-960X

Correo electrónico: germanayalaosorio@gmail.com; gayala@uao.edu.co

*Artículo de reflexión derivado de investigación. 


\section{Comunicación y estética-ética: el caso del monocultivo de la caña de azúcar'}

\section{La comunicación y sus conexiones}

Se asume la comunicación como un proceso natural ${ }^{2}$ complejo $^{3}$ y definitivo dentro y para el decurso de la consolidación del proyecto humano moderno; a pesar de las disímiles maneras en las que la especie humana ha logrado poblar el planeta Tierra y erigirse, en millones de años, como la especie dominante dentro de las lógicas y las relaciones de la cadena trófica. De allí que la comunicación obedezca y dé cuenta de un proceso de consolidación de la experiencia humana. Así mismo, se entiende como una práctica, un saber, un proceso, una posibilidad y una proto-disciplina que deviene histórico-cultural y en la que están inmersos los seres humanos y los no humanos que viven $-\mathrm{y}$ sobreviven - en y dentro de las relaciones Sociedad-Naturaleza. Si bien la comunicación en su condición ontológica deviene interdisciplinar, compleja, sistémica y contextual, los desarrollos de la ciencia moderna y las disciplinas dominantes dejaron relegada esta dimensión de lo humano, reduciéndola ${ }^{4}$ al intercambio de información y, por lo tanto, a un instrumento que está por fuera de la condición humana y sujeto a la construcción y el uso interesado de equipos y tecnologías para la entrega de información (datos).

\footnotetext{
${ }^{1}$ Este texto hace parte del proceso de formación doctoral de su autor. Las disquisiciones aquí planteadas hacen parte del tema de investigación doctoral con el que recibió en 2019. El título del proyecto de investigación es: Intervención del Estado en la consolidación de la agroindustria de la caña de azúcar en el valle geográfico del río Cauca y sus efectos en la sostenibilidad ambiental regional (1990-2019).

${ }^{2}$ En condiciones cognitivas, todo ser humano está facultado para establecer diálogos con otros, generar condiciones y ambientes dialógicos. Es natural porque el ser humano viene dispuesto genéticamente para hablar. La lengua habita en él como una facultad y el lenguaje es construido en el proceso civilizatorio en el que está instalado.

${ }^{3}$ Morin define la complejidad así: “Al mirar con más atención, la complejidad es, efectivamente, el tejido de eventos, acciones, interacciones, retroacciones, determinaciones, azares, que constituyen nuestro mundo fenoménico. [...] La dificultad del pensamiento complejo es que debe afrontar lo entramado (el juego infinito de inter-retroacciones), la solidaridad de los fenómenos entre sí, la bruma, la incertidumbre, la contradicción" (Morin, 2011, p. 32).

${ }^{4}$ En particular, los programas de formación universitaria de comunicación social-periodismo aportaron negativamente al posicionamiento de la Comunicación como campo disciplinar.
} 
Sectores de la ciencia y de las comunidades científicas ${ }^{5}$ parecen haber olvidado que la comunicación, ontológicamente, está sujeta a una condición humana compleja ${ }^{6}$, contradictoria, conflictiva y potencialmente democrática, resultado de esas condiciones propiamente humanas. Entonces, la comunicación se entiende desde la posibilidad de fracasar en términos de lograr encuentros dialógicos y simétricos, el logro o no de consensos, momentos de reconocimiento de las diferencias entre racionalidades, identidades y condiciones de (a)simetría ${ }^{7}$. Cuando se dan situaciones y escenarios comunicativos en los que se confrontan discursos, posturas, emocionalidades, subjetividades y se ponen en cuestión decisiones que se deben tomar, en el marco de unos modelos mentales y órdenes simbólicos dominantes que de muchas maneras impactan los ecosistemas, se está en condiciones óptimas de simetría.

Y como proceso de interacción humano, la comunicación está conectada con el tipo de relaciones que el ser humano y la sociedad construyeron con la naturaleza ${ }^{8}$. Relaciones que pasan por valoraciones y emociones/emocionalidades articuladas a unas subjetividades fuertemente ancoradas a procesos civilizatorios no asociados exclusivamente a los principios y objetivos de lo que se conoce como el proyecto moderno europeo. Es decir, que todos los procesos de dominación y domesticación de los ecosistemas que componen lo que se conoce como naturaleza, en sí mismos responden a un problema o asunto comunicativo, ético ${ }^{9}$ y estético ${ }^{10}$, en la medida en que el desarrollo económico, basado en la extracción

\footnotetext{
${ }^{5}$ En referencia a científicos sociales y a otros de las llamadas ciencias duras, que miran con desdén a la comunicación, justamente, porque la reducen a un intercambio de información, al procesamiento de datos o al diálogo que sucede en escenarios comunicativos institucionales, formales y no formales, en los que las interacciones y las intencionalidades no se miden o se califican.

${ }^{6}$ Los animales no humanos también se comunican, mediante diversos tipos de lenguajes.

${ }^{7}$ Entiendo como condiciones de simetría aquellas en las que a pesar de que subsistan en situaciones comunicativas relaciones de poder entre los participantes de estas situaciones, esas relaciones de poder no terminan en formas de dominación y yuxtaposición de unos sobre otros. El logro de mínimos consensos constituye el principio básico de un encuentro comunicativo simétrico. Esta perspectiva es contraria a la planteada por Latour: "Simetría es un término que puede definirse como aquello que se conserva a través de las transformaciones. En la simetría entre los humanos y los no humanos, mantengo constante la serie de competencias, de propiedades que los agentes pueden intercambiar si se superponen unos a otros" (2001, p. 218).

${ }^{8}$ Decía Marx que la Naturaleza "es el cuerpo inorgánico del hombre, es decir, la naturaleza en cuanto no es ella misma el cuerpo humano. El hombre vive de la naturaleza; esto quiere decir que la naturaleza es su cuerpo, con el que debe permanecer en un proceso continuo, a fin de no perecer. El hecho de que la vida física y espiritual del hombre depende de la naturaleza no significa otra cosa, sino que la naturaleza se relaciona consigo misma, ya que el hombre es una parte de la naturaleza" (Citado en Tagliavini y Sabbatella, 2011).

${ }^{9}$ Hace referencia a actitudes, acciones y prácticas que dan cuenta del tipo de relaciones, simétricas o de dominación, entre seres humanos y entre estos y el entorno, caracterizadas por la comprensión y el respeto de las diferencias, que finalmente lleven al ser humano a ubicarse en estadios de mejoramiento, de excelencia y de un virtuosismo que minimicen los riesgos latentes de vivir juntos.

${ }^{10}$ Hace referencia a la emocionalidad, al goce, al disfrute, a la espiritualidad, a procesos de deificación, de exaltación y de relacionamiento que alimentan particulares subjetividades.
} 
de minerales y en la especialización agrícola, entre otras prácticas, exhibe formas y ejercicios representacionales no solo alrededor de la naturaleza, sino en torno a esos otros grupos humanos que históricamente establecieron tipos de relacionamientos y ejercicios representacionales distintos con el entorno natural (la base ecosistémica), en la medida en que devienen consustanciales a la vida humana misma: indígenas, campesinos y afrocolombianos. Justamente, en relación con esos otros, histórica y culturalmente distintos al Hombre Blanco ${ }^{11}$ occidental que responde con claridad y eficacia simbólica a la identidad homogénea del proyecto moderno (hombre blanco), se escenificó en esta parte de América y en particular en Colombia, un proceso de igualamiento negativo ${ }^{12}$ entre la naturaleza y esos otros cuyas vidas estaban ancladas a unos órdenes simbólicos y culturales abiertamente contrarios al orden que el proyecto de la euro modernidad impuso y naturalizó.

El proceso de igualamiento negativo hizo posible fundir, o por lo menos hacer confluir, en una sola idea de 'enemigo' a la naturaleza entendida como ese complejo escenario de relaciones y conexiones ecológicas y ambientales, y a quienes exhibían prácticas de intervención no impregnadas de los principios de domesticación de los ecosistemas, tal y como lo plantearon los agentes del desarrollo. Por esa vía, el igualamiento negativo, como categoría, emerge para dar vida explicativa y comprensiva a los procesos de domesticación, no solo de la naturaleza, sino de todos aquellos grupos humanos que establecieron de manera temprana relaciones inmanentes con un entorno natural que sufría, de tiempo atrás, las intervenciones de una idea de desarrollo en el marco de una modernidad europea.

De ese modo, el orden simbólico jugó un papel clave en el sentido en que sirvió para validar las apuestas desarrollistas, aupadas de muchas maneras por dos sentimientos que terminaron fusionados a la idea moderna de desarrollo: de un lado, el de superioridad, y del otro, el de impotencia que el ser humano sintió frente a una naturaleza que no solo lo retó en su capacidad e inteligencia, sino que lo sometió -y somete aún- en muchos momentos, a la fuerza de eventos naturales (terremotos, huracanes), que lo "convencieron" de la necesidad de continuar con el proceso de sometimiento y domesticación de la naturaleza, apelando a la razón y a la ciencia.

\footnotetext{
11 Además, debía ser "heterosexual, tener propiedad, una profesión u oficio reconocido y valorado social y económicamente, padre de familia y letrado" (Castro-Gómez, 2000, p. 149).

${ }^{12}$ Como parte de este ejercicio reflexivo, el autor propone esta categoría para dar cuenta del proceso comunicativo que permitió que agentes desarrollistas asumieran y se representaran específicos grupos humanos, como indígenas, afros y campesinos, como disonantes y "enemigos" a vencer. El Igualamiento Negativo se da desde el preciso momento en el que se igualan, se ponen en el mismo nivel y como objetivos a vencer, accidentes geográficos y ecosistemas que, al igual que dichas comunidades, impedían el desarrollo económico y la consolidación del proyecto moderno.
} 
Ante la "debilidad humana" la cultura se enfrenta a la naturaleza para domesticarla. La modernidad tendió hacia la disolución de la naturaleza hasta la aparición de los discursos ecologistas de la era multicultural. [...] La trayectoria del deseo civilizador es un largo viaje hacia la desaparición ontológica de la naturaleza. El objetivo de la racionalidad es desenajenarse de la naturaleza, que es vista como un lugar que amenaza con destruir y desestabilizar la cultura. Lo natural es lo ilimitado, lo desordenado, lo instintivo, lo emotivo, aquella moralidad negativa que el deber ser moderno reprime y penaliza (Gnecco, 2008, p. 116) ${ }^{13}$.

Entre tanto Castro-Gómez sostiene, al referirse al proyecto moderno en el que se anclan las ideas de desarrollo y progreso que,

Ya no es la voluntad inescrutable de Dios quien decide sobre los acontecimientos de la vida individual y social, sino que es el hombre mismo quien, sirviéndose de la razón, es capaz de descifrar las leyes inherentes a la naturaleza para colocarlas a su servicio. Esta rehabilitación del hombre viene de la mano con la idea del dominio sobre la naturaleza mediante la ciencia y la técnica [...] (2000, p. 149) ${ }^{14}$.

Tanto Gnecco como Castro-Gómez, sin que ese sea su propósito, dan cuenta de la comunicación como un proceso histórico, cambiante y fluido, en el que sobresalen ejercicios representacionales, no solo en torno a esos otros seres humanos, sino a esos otros seres vivos e inanimados y al conjunto de la naturaleza, que finalmente terminó domesticada y sometida a la lógica del capital. En esa misma línea, la comunicación puede ser entendida como el metarrelato de realidades humanas complejas. Igualmente, la comunicación puede servir como dispositivo de análisis para comprender las relaciones establecidas entre la sociedad y la naturaleza.

Como animal cultural ${ }^{15}$ u homo communicatio ${ }^{16}$ el ser humano se apropia

\footnotetext{
${ }^{13}$ Las cursivas son propias.

${ }^{14}$ Las cursivas son propias.

${ }^{15}$ En la Encíclica Laudato si', sobre el cuidado de la casa común, del Papa Francisco, se lee que "el problema es que no disponemos todavía de la cultura necesaria para enfrentar esta crisis y hace falta construir liderazgos que marquen caminos, buscando atender las necesidades de las generaciones actuales incluyendo a todos, sin perjudicar a las generaciones futuras... necesitamos fortalecer la conciencia de que somos una sola familia humana" (Francisco, 2015, p. 17).

${ }^{16}$ De la misma manera como se asume la existencia del homo sapiens sapiens y el homo faber, entre otros, es importante reconocer al homo communicatio porque su importancia radica en que está inmerso en un proceso histórico de interacción simbólica sobre el que se gira la comunicación y de allí se desprenden ejercicios dialógicos y analíticos de lo que el ser humano ha hecho en Su largo proceso de humanización.
} 
del mundo natural a través del lenguaje $\mathrm{e}^{17}$ y de acciones ancoradas a múltiples subjetividades y, con estas, de los discursos con los que no solo se legitima como especie dominante, sino que emprende o consolida acciones de dominación sobre la naturaleza y sobre sus propios congéneres. El discurso científico y los desarrollos de la ciencia son la expresión primigenia de un ser humano capaz de crear mundos paralelos ${ }^{18}$, al tiempo que establece e impone sobre el planeta prácticas civilizatorias que de forma radical han transformado el paisaje natural, hasta el punto de que ya se asegura, desde el mismo potencial discursivo, de interacción, dialógico y representacional, que hoy la sociedad humana asiste y deviene en una etapa Ilamada Antropoceno ${ }^{19}$.

Lo expuesto hasta el momento refleja la intención de un ejercicio relacional que busca establecer conexiones, interacciones y prácticas dialogantes o encuentros dialógicos entre ciencias, campos de estudio y disciplinas; propiciados dichos encuentros dialógicos a partir de una práctica-realidad agroindustrial ${ }^{20}$ a la que se le reconocen numerosos impactos socio ambientales: el monocultivo de la caña de azúcar. A pesar de la intención manifiesta de relacionar, Morin asume dicho ejercicio como una aventura compleja:

Creo que aún estamos muy lejos de entender la necesidad de relacionar; relacionar es sin duda el gran problema al que va a tener que enfrentar la educación [...] hoy, todos esos conocimientos fragmentarios tienen algo mortal. Hemos creado catástrofes naturales desviando ríos en Siberia o levantando presas de agua de forma irreflexiva, destruimos culturas en virtud de una lógica económica cerrada. Se ha desarrollado lo que yo llamaría una

\footnotetext{
${ }^{17}$ La arbitrariedad del signo lingüístico de la que habla Ferdinand de Saussure es la prueba fehaciente del poder no solo de la comunicación como factor al que se ve abocado el ser humano, sino de las enormes posibilidades que se abren en términos de nombrar y re-nombrar, si es el caso, la realidad que siempre devendrá construida y re-construida. Se advierte que la apropiación del mundo no solo se da a través del lenguaje, sino a través del poder, de su ejercicio práctico; igualmente, a través del conocimiento.

${ }^{18}$ En referencia a los mundos míticos, a la posibilidad de imaginar mundos posibles, a soñar y finalmente, a la capacidad de pensar utopías y relatos que hagan extender en el tiempo la voluntad humana de insistir en estar en el mundo.

19 “El Antropoceno designa una nueva época geológica cuyo rasgo central es el protagonismo de la humanidad, convertida ahora en agente de cambio medioambiental a escala planetaria" (Arias, 2018, p. 14),

${ }^{20}$ Esta actividad agroindustrial está soportada en desarrollos técnico-científicos que se han venido naturalizando de tal forma, que en sí mismos expresan relaciones de poder y de dominación no solo de una base ecosistémica totalmente transformada como la del valle geográfico del río Cauca (Cauca, Valle y Risaralda), sino de comunidades indígenas, afros y campesinas. "La habilidad, el conocimiento de la técnica, se constituye así en una forma de poder, en una relación en la que hombre y mundo se transforman" (Gamboa, 2014, p. 256).
} 
inteligencia ciega para los contextos, que ha perdido toda capacidad de concebir los conjuntos. Pero vivimos en un mundo en el que todo comunica e interactúa (Morin y Cyrulnik, 2005, pp. 11-12).

\section{El monocultivo de la caña de azúcar: desde la ética, la estética y la comunicación política}

Para el caso de la agroindustria ${ }^{21}$ cañicultora o cañera en el valle geográfico del río Cauca ${ }^{22}$ y su largo proceso de consolidación, la comunicación y la estética emergen como campos de saber y de acción importantes y definitivos en lo analítico, en la medida que, en la hegemonía de este monocultivo, se reconocen asuntos y circunstancias ancoradas a las relaciones Sociedad-Naturaleza y, por supuesto, a los discursos con los que agentes de Estado y de la sociedad civil validan y legitiman la presencia de este sistema de producción agrícola, pasando por encima de aquellas discursividades, subjetividades y emocionalidades que confrontan a esta agroindustria y a la perspectiva estética que la respalda, en particular aquellas emanadas de comunidades campesinas y pueblos afrocolombianos e indígenas, asentados a lo largo y ancho de los territorios que conforman lo que se conoce como el valle geográfico del río Cauca y en los que sobreviven dentro de los territorios de Florida y Miranda, entre otros municipios.

¿Qué elementos hacen posible la conexión entre la comunicación y la estética?, son varios, a saber. En primer lugar, se asume la estética como una acción valorativa de algo que llama la atención de un ser humano, en tanto dicho llamado de atención está soportado en emocionalidades que ese "algo" despierta en quien es interpelado; de igual manera, aparecen dentro de las emocionalidades expuestas, la acción de goce, y los procesos de deificación, de exaltación y de relacionamiento que alimentan particulares subjetividades ${ }^{23}$ que se suscitan en la experiencia comunicativa-estética evidenciada. Piénsese en la contemplación de un paisaje o de una matriz dominante que, para el caso del valle geográfico del río Cauca, es el monocultivo de la caña de azúcar. Por supuesto que se estaría ante una experiencia comunicativa-estética en la medida en que ocurre una interacción subjetivada, emotiva y sugerente entre quien aprecia el paisaje

\footnotetext{
${ }^{21}$ Se trata de una realidad compleja que contiene o se expresa en la consolidación de un clúster económicamente sólido; se está ante un ejercicio de poder y de dominación de la naturaleza. Y de manera concomitante, la agroindustria es un estadio "superior" de la agricultura, vista esta última como una técnica con históricos efectos socioambientales, negativos y positivos.

22 Incluye a los departamentos de Cauca, Valle del Cauca y Risaralda.

${ }^{23}$ A propósito de la representación y de la subjetividad, Kant señala: "lo que en la representación de un objeto es meramente subjetivo, es decir, lo que constituye su relación con el sujeto y no con el objeto, es la cualidad estética de la misma [...] lo subjetivo, empero, en una representación, lo que no puede de ningún modo llegar a ser un elemento de conocimiento, es el placer o el dolor que con ella va unido, pues por medio de él no conozco nada del objeto de la representación, aunque él pueda ser el efecto de algún conocimiento" (Kant, 2013, p. 114).
} 
(natural-histórico ${ }^{24}$ ) o la matriz cañera. Tanto la estética y la comunicación son formas de acción y de interacción simbólicas, que ocurren dentro de modelos mentales específicos y un orden simbólico dominante que facilita o entorpece el encuentro comunicativo.

Aunque la siembra y cosecha de la caña de azúcar son parte sustantiva de la actividad agroindustrial cañera, que deviene compleja ${ }^{25}$ desde la perspectiva técnica ${ }^{26}$, esa circunstancia no aleja al cultivo de esta gramínea del campo de la agricultura. En ese sentido, cobra gran valor lo expresado por Ángel Maya cuando señaló que,

La intervención de la agricultura significó la mayor revolución tecnológica, anterior a la revolución industrial y modificó profundamente las leyes ecosistémicas. Hacer agricultura es crear un ambiente artificial para algunas especies, separándolas de su nicho ecológico, para beneficio del hombre y en contra de muchas especies que desde ese momento empiezan a recibir el nombre denigrante de "maleza" o "plaga". La deforestación de amplias zonas y los cultivos intensivos de algunas regiones influyeron en la construcción o destrucción de las culturas y el desarrollo de estas incidió en la transformación del medio (1991, p. 11).

La condición de ser una instalación artificial no es óbice para que sobre el monocultivo de la caña de azúcar y la actividad agroindustrial que desata la plantación, sean posibles encuentros comunicativos y estéticos. Así, desde la comunicación y la estética se pueden valorar las circunstancias, razones, intenciones y decisiones que facilitaron y permitieron, desde el Estado y la sociedad, la consolidación del cultivo de la caña de azúcar en las municipalidades de Florida y Miranda, como ejemplos tipo de lo que sucedió y sucede aún en el macro territorio llamado valle geográfico del río Cauca.

Sin embargo, las valoraciones que se puedan hacer al invocar a la comunicaciónestética pueden resultar insuficientes para el ejercicio científico tradicional. De allí que sea necesario traer a colación un campo relativamente novedoso para hacer análisis contextuales de fenómenos y de hechos: la comunicación política que, asumida como proceso,

\footnotetext{
${ }^{24}$ Alude a ecosistemas naturales de los que no se puede asegurar que son prístinos, por cuando la presencia humana en ellos expresa tipos de alteraciones, perturbaciones y cambios en su estructura ecológica.

25 “Los sistemas ambientales, son sistemas complejos. [...] El carácter de «complejo» está dado por las interrelaciones entre los componentes, cuyas funciones dentro del sistema no son independientes. El conjunto de sus relaciones constituye la estructura, que da al sistema la forma de organización que le hace funcionar como una totalidad" (García, 1994, p. 94).

${ }^{26}$ En referencia a los procesos productivos y a los dispositivos técnicos para el procesamiento de la caña y la extracción de los jugos azucarados (sacarosa) y, finalmente, el logro del azúcar.
} 
[...] es tributaria de las condiciones económicas, políticas, culturales y sociales que históricamente han predominado en el fortalecimiento de un régimen político, en el logro de su legitimidad y viabilidad a futuro. Por ello, describir cómo son los escenarios de la comunicación política en un determinado entorno social supone recoger los elementos históricos característicos del devenir de un determinado orden social, en donde sobresalen las formas relacionales manifiestas y no manifiestas entre las instituciones estatales, entre estas y las que agencian los intereses de la sociedad civil, especialmente los gremios económicos [...] (Ayala, 2006, p. 148).

Así, la consolidación del monocultivo de la caña de azúcar en los territorios de tres departamentos del suroccidente colombiano obedece a particulares condiciones contextuales (sociales, económicas, políticas y culturales), en el marco del proceso continuo de construcción de Estado-sociedad-mercado.

La comunicación política hace evidente la confluencia de factores, perspectivas y campos, desde la perspectiva de Bourdieu. Además de la estética, la ética, en particular la ética ambiental, aparece como un factor clave. De esta forma, la ética y la estética ambientales ${ }^{27}$ nacen como campos de estudio desde los cuales es posible comprender la relación sociedad-naturaleza y quizás proponer acciones de cambio, dados los problemas socio ambientales generados por la especie humana, derivados y anclados todos a un tipo de ética y a una particular estética derivada de un modelo de desarrollo dominante.

Para efectos de este artículo, se propone hablar de estética-ética en la perspectiva planteada por Ana Patricia Noguera, quien propone dejar atrás las escisiones de la modernidad y buscar un re-encantamiento del mundo a partir de un nuevo ethos que permita proscribir o por lo menos debilitar ese ethos del habitar bajo relaciones de dominio ${ }^{28}$ que caracteriza al mundo moderno con todo y su racionalidad tecno científica. En la Tabla 1. se proponen algunos elementos fundantes para pensar en una estética-ética ambiental. Noguera expresa la necesidad de "[...] construir una ética-estética del respeto, del agradecimiento, de la emoción y del culto entre seres humanos que habitan, como cuerpos simbólicobióticos y mundo-de-la-vida-simbólico-biótico" (Noguera, 2004).

\footnotetext{
${ }_{27}$ Se entiende lo ambiental desde la perspectiva de Ángel Maya, que establece la conexión ontológica entre cultura y ambiente, esto es, formas de apreciar y relacionarse con los ecosistemas. Al respecto, Augusto Ángel Maya señala lo siguiente: "Mientras no se hayan comprendido las complejas articulaciones del sistema social, no es posible entender la naturaleza en su conjunto, tal y como existe hoy en día. Ello significa que el orden natural incluye igualmente en la actual etapa evolutiva, el orden humano. Ahora bien, el orden humano no coincide necesariamente con el orden ecosistémico no tiene por qué coincidir. La solución al problema ambiental no consiste en encajar al hombre dentro del ecosistema. No consiste, por tanto, en saber «conservar», sino en aprender a «transformar bien». La especie humana no tiene ninguna alternativa evolutiva, sino la transformación del orden ecosistémico" (2009, pp. 16-17).

${ }^{28}$ (Cfr. Noguera, 2004).
}

Revista Filosofía UIS, vol. 19 n. ${ }^{\circ}$, enero - junio de 2020 
Tabla 1. Elementos para pensar una estética-ética ambiental

\begin{tabular}{|c|c|}
\hline \multicolumn{2}{|c|}{ Elementos para pensar una estética-ética ambiental } \\
\hline Actitud & $\begin{array}{l}\text { Frente a la vida y a los otros, haciendo consciencia de } \\
\text { los problemas que conlleva el pensamiento escisional }{ }^{29} \\
\text { moderno. Se espera que los ciudadanos asuman posturas y } \\
\text { actitudes sistémicas y relacionales que los lleven a estadios } \\
\text { comprensivos de asuntos y realidades complejas. }\end{array}$ \\
\hline Aptitud & $\begin{array}{l}\text { Cognitiva, relacionamiento y conexiones disciplinares } \\
\text { y no disciplinares. Capacidad para integrar visiones, } \\
\text { reconocer paradigmas y confrontar realidades complejas. } \\
\text { Los procesos escolarizados formales y no formales deben } \\
\text { apuntar al desarrollo de aptitudes en este sentido. }\end{array}$ \\
\hline Espiritualidad & $\begin{array}{l}\text { Disímiles formas de vibrar y de establecer relaciones } \\
\text { afectivas y amorosas con las manifestaciones de la Vida. } \\
\text { No confundir con religiosidad. Recoger el sentido ético- } \\
\text { estético y comunicativo que tiene la categoría o concepto } \\
\text { sentipensantes. }\end{array}$ \\
\hline Emocionalidad & $\begin{array}{l}\text { Relacionada con las emociones, los sentimientos y los } \\
\text { estadios de contemplación que genera el contacto con la } \\
\text { Naturaleza y el goce a través de los sentidos. Este factor } \\
\text { resulta clave para contrastar, con el caso de la práctica } \\
\text { del monocultivo de la caña de azúcar, qué sensaciones y } \\
\text { emociones produce en cada ciudadano verse rodeado por } \\
\text { grandes extensiones de tierra sembradas de esta gramínea. }\end{array}$ \\
\hline $\begin{array}{l}\text { Responsabilidad } \\
\text { socio- ambiental }\end{array}$ & $\begin{array}{l}\text { Desde la condición de ciudadano, se reconoce una actitud } \\
\text { de co-responsabilidad con los ecosistemas. Asumirse } \\
\text { como co-responsable de las afectaciones ecológicas y las } \\
\text { transformaciones estéticas de la Naturaleza será posible } \\
\text { cuando habitantes citadinos modifiquen sustancialmente } \\
\text { sus representaciones sociales en torno a la consecución } \\
\text { del éxito y a la idea moderna que se impuso a hombres y } \\
\text { mujeres de "realizarse". }\end{array}$ \\
\hline
\end{tabular}

Fuente: elaboración propia

Así, el monocultivo de la caña de azúcar es, en sí mismo, una apuesta ética-estética en la que confluyen de manera conflictiva modos y ejercicios

\footnotetext{
${ }^{29}$ Se alude al pensamiento escisional aquel que, anclado al proyecto de la modernidad o de la euromodernidad al decir de Arturo Escobar, insiste en estudiar los fenómenos naturales y humanos de manera separada, estableciendo cortes, escisiones, divisiones y por esa vía, estableciendo dualidades ficticias. Desde la perspectiva médica, se propone el carácter escisional en el sentido de "extirpar" del discurso toda acción que insista en construir y consolidar dualidades.
} 
representacionales de agentes de poder (dominantes y subordinados), que deben mirarse en el marco de órdenes simbólicos diametralmente distintos (entre agentes aupadores del monocultivo, como cañicultores privados y comunidades campesinas, afros e indígenas que disponen de la tierra y de los territorios para el desarrollo de prácticas propias de la agricultura tradicional).

Si bien Noguera propone hablar de estética-ética, como ejercicio analítico es preciso separar, para los propósitos de este trabajo, las dos categorías que la filósofa unió para sus fines argumentales. Para el caso de la ética, se asume como una apuesta de vida, en el marco de constantes ejercicios representacionales de miembros de una sociedad que creen posible consolidar proyectos de vida individual y colectiva soportados en un norte que, aunque allende, se asume como alcanzable: la excelencia humana. Esto es, una condición de máximo crecimiento espiritual de los miembros de una especie humana compleja por las dimensiones identitarias que confluyen en cada uno de los sujetos humanos. Al final, esa excelencia humana, llena de virtudes, da cuenta de una eticidad capaz de ponerle freno a las pulsiones, a las contradicciones y a las expresiones violentas, simbólicas y físicas de una condición humana que se autoimpone límites, para evitar los efectos de disímiles formas de actuar, pensar, decir y sentir, generadoras en últimas de conflictos que deben ser resueltos éticamente. Polo Santillán dice que "la ética no es sólo un asunto entre seres humanos, sino también tiene que ver con la relación entre los hombres y la naturaleza, porque ella sustenta nuestro ser" $^{\prime \prime}$ 2005, p. 29) $)^{30}$.

Y como parte del proceso histórico de dominación de la naturaleza, la ética ambiental emerge como una oportunidad y quizás como un camino para afrontar, confrontar, revisar y quizás proscribir aquellas prácticas ambientales éticamente insostenibles. Ramón Folch sostiene que:

los humanos más evolutivamente avanzados, en definitiva, son los humanos que se auto proporcionan una ética reguladora de sus actuaciones ambientales. Por eso, a mi entender, la ética ambiental es más que necesaria: es el fatal corolario de la propia evolución humana [...] de ahí el reto y la paradoja de la ética ambiental: es una necesidad evolutiva (moral, o sea del intelecto), en la medida en que solo contrariando la estrategia evolutiva (física, o sea, material) se podrá garantizar la continuidad de la propia especie en su sistema. En otras palabras: al menos por razones prácticas, necesitamos alumbrar una nueva y socioecológicamente avanzada moral ambiental [...] Los humanos se auto contemplan como los reyes de la creación, cuyos recursos están enteramente puestos a su servicio. No ven limitaciones morales a la explotación de la naturaleza (Id y dominad la Tierra), lo cual excluye toda limitación ética de partida en las relaciones con el entorno (1998, pp. 32-34).

${ }^{30}$ Véase http://revistasolar.org/numero-10-1/ 
La desconexión entre el ser humano y la naturaleza se instaura a partir del "yo cartesiano", en el sentido en que este aseguró la ruptura entre razón y naturaleza y la consecuente dominación ejercida sobre esta (Noguera, 2018, p. 30), lo que terminó demostrando y explicitando el verdadero talante del ser humano moderno: homogeneizador, depredador y profundamente arrogante frente a una naturaleza a la que muy seguramente se sintió atado, esto es, preso y confrontado por las liberadoras fuerzas estéticas de aquellas comunidades humanas capaces de sentirse y ser parte de la naturaleza, establecer relaciones consustanciales y de entender las conexiones rizomáticas ecológicas y ambientales (culturales).

Hay, entonces, un sentir-actuar-pensar ético en quienes no se ponen por encima de la naturaleza. Un sentir que quizás los intente llevar por los caminos que los llevase a convertirse en seres virtuosos ambientalmente hablando. Por el contrario, el sentir-actuar-pensar ético de aquellos agentes domesticadores de la naturaleza no está en el camino de la búsqueda de la excelencia del ser o de ese ser virtuoso ambientalmente, más bien, transita por las veloces autopistas del empobrecimiento de la experiencia humana en la que se niegan las conexiones rizomáticas que los atan a la naturaleza, y que insisten en negar o en horadar, a través de ejercicios representacionales profundamente cargados de un sentido utilitarista y de máximo aprovechamiento de la naturaleza, vista, simple y únicamente, como proveedora de recursos. Noguera propone hablar poéticamente, lo que significa

Despojarnos de los símbolos de dominio, propiedad y explotación, que han tejido la trama de la cultura moderna, para adelantar una tarea lenta, difícil, heterotópica y distópica: abandonar el sujeto y la subjetividad, el objeto y la objetividad; renunciar al piso seguro de las categorías universales; aceptar la inmanencia de lo humano, nuestro arraigo en la naturaleza, como un hilo más en el complejo tejido de la vida (2018, p. 27).

En lo que respecta a la estética ${ }^{31}$, esta se asume, en un doble sentido y propósito, como un dispositivo representacional asociado a formas de relacionamiento entre la sociedad y la naturaleza y, en particular, entre agentes de poder dominante y agentes subordinados al orden cultural moderno; y como herramienta de análisis sistémico a través de la cual es posible valorar, estéticamente, las prácticas discursivas, las acciones y las determinaciones del poder, el propio modelo económico y los diversos procesos de domesticación, transformación o de aprovechamiento (in)sostenible de ecosistemas naturales-históricos.

\footnotetext{
${ }^{11}$ Para efectos de este texto, se sigue la perspectiva de la estesis planteada por Mandoki, vista "como un proceso que caracteriza a los organismos vivos, en la medida en que los abre al mundo y los dispone a lo sensorial. La estesis es resultado de la condición corporal de cada ser viviente, específicamente de su condición membranada, porosa (desde la membrana celular a la epidermis, la retina, el tímpano, la membrana olfativa y gustativa) que nos permite detectar, tocar, ver, oír, oler y degustar con mayor o menor detalle y complejidad [...]" (2006, pp. 13-14).
} 
En nuestro caso, el monocultivo de la caña de azúcar es la expresión de una estética del poder, de la economía, del desarrollo y de la naturaleza, con la que no solo se valoran y se establecen parámetros de goce, sino que se proponen criterios de emocionalidad universal asociados, por supuesto, a una idea igualmente universal de desarrollo. La dimensión estética está ontológicamente atada a una condición humana compleja que, al haberse dado el lugar de especie dominante y con capacidad transformadora de los ecosistemas, de la naturaleza y del planeta mismo, de inmediato estableció, con la ayuda del lenguaje, relaciones dicotómicas altamente generadoras de ejercicios representacionales que terminaron validando la ética y la estética de los agentes de un desarrollo insostenible, que nos ha puesto a todos en modo de resiliencia, quizás porque ya no hay forma de echar hacia atrás el actual modelo de desarrollo y, en particular, las relaciones entre la sociedad y la naturaleza.

Un ejemplo de esas relaciones duales es el que se expresa en naturaleza amable-naturaleza inhóspita ${ }^{32}$. De la primera, hicieron y hacen parte todos aquellos ecosistemas que brindaban condiciones de fácil sometimiento y de penetración física de comunidades humanas; de la segunda, hacen e hicieron parte aquellos paisajes y ecosistemas que ofrecían resistencia a grupos humanos que los vieron como fuertes obstáculos para alcanzar una idea de desarrollo. En particular, los humedales y, en general, las condiciones naturales que obligaban la implementación de obras y acciones propias de la ingeniería civil, para poder superarlas y lograr avanzar en el proceso de domesticación de la naturaleza.

Así, la estética es una dimensión humana que trasciende la contemplación del mundo a través del arte (lo bello) y, por ese camino, se instala como una suerte de factor representacional de aquello que el ser humano, a través del lenguaje como dispositivo nominador, y las emocionalidades, decide qué es sublime y digno de conservarse o aprovecharse, estableciendo unos límites que, si bien los establece la ciencia, deberían pasar también por valoraciones estéticas. La estética-ética o la ética-estética pone en cuestión el carácter dual, dicotómico y escisional del mundo moderno y se abre paso como herramienta comprehensiva de los fenómenos socio ambientales, en la medida en que apunta a establecer miradas y análisis holísticos, sistémicos, pero, sobre todo, acciones discursivas y prácticas sostenidas por altas dosis de emocionalidades y de formas de sentir-pensar lo humano-natural. De esa forma, es posible superar la mirada utilitarista sobre esa proveedora de recursos Ilamada Naturaleza. Noguera sostiene que,

La tragedia de la escisión fundacional de Occidente consiste en habernos creído amos y señores del tejido de la vida, cuando apenas somos un hilo de su trama; haber creído que la libertad consistía en dominar la naturaleza, cuando aquella apenas es una emergencia de esta; haber creído en la infinitud de la razón cuando esta es una mínima parte de lo humano; haber

32 Estas categorías las propone el autor. 
creído ser seres humanos sin naturaleza, cuando solo es posible serlo en esta; haber despreciado la tierra, cuando se trata de nuestra madre; haberla reducido a objeto, cuando se trata de un enigma maravilloso, indescifrable y misterioso; haber creído que la ciencia puede explicar la vida, cuando esta no se puede apresar en una fórmula matemática, en un dato, en una cuantificación. La tragedia de esta civilización ha sido, en suma, haber creído que la naturaleza era de su propiedad, cuando somos los humanos los que nos debemos a la naturaleza [...] La cultura moderna se consolidó gracias a la creencia de que la naturaleza era ilimitada y estaba disponible como recurso para la racionalidad tecno científica infinita del ser humano (2004, pp. 20-22).

El modelo de desarrollo, ancorado en el modelo unívoco de la modernidad, expresa en sí mismo una postura ética y estética que desdice de posturas conducentes al respeto de ese otro no humano con el que el ser humano interactúa, bien desde una lógica de aprovechamiento (extracción y explotación) sobre la base de unos reconocidos servicios ecosistémicos o, quizás, desde una perspectiva estética que no solo pone de presente el goce a través de todos los sentidos, con todo y las diferencias dadas por el dominio del sentido de la visión; las emociones y el carácter espiritual con el que son asumidos y valorados los ecosistemas naturales-históricos, sino el profundo respeto por la funcionalidad de unos ecosistemas que desde la estética puedan ser valorados y, sobre ellos, exponer una deontología ecosociosistémica y unas obligaciones humanas (un deber) que desde la comunicación política exigen al Estado y a la sociedad jugar un papel preponderante y conducente a la consolidación de un modelo de desarrollo y unas prácticas agrícolas viables desde la perspectiva de la sostenibilidad.

Como se advirtió en líneas precedentes, la comunicación se asume como un proceso histórico de interacciones en el que se dieron y se dan ejercicios representacionales desde, por y entre grupos de poder dominante (Agentes de Poder) y comunidades "subordinadas" y afectadas por las disímiles acciones emprendidas por élites del poder dominante (del Establecimiento). Acciones de tipo económico, como la imposición de un modelo de agricultura; de tipo político, como la captura del Estado y la expresión de actos estatales contrarios a las expectativas y a los derechos de los llamados Agentes comunitarios de poder (comunidades negras y campesinas y pueblos indígenas); igualmente, acciones de tipo simbólico, asociadas a un discurso modernizante y modernizador que desconoce las cosmovisiones y los órdenes simbólicos de negros, campesinos e indígenas.

Entonces, la comunicación se asume, entre otras de las perspectivas ya señaladas líneas atrás, como un campo de comprensión, confrontación, análisis y aprehensión de hechos, acciones, decisiones, discursos y prácticas socioculturales y ambientales. Desde la comunicación es posible develar intencionalidades y 
motivaciones, así como conflictos representacionales que se dan entre aquellos que histórica y culturalmente han establecido una relación de respeto consustancial e inmanente con la naturaleza y de aprovechamiento sostenible de sus elementos constitutivos, y aquellos que consolidaron una relación caracterizada por el sometimiento y el aprovechamiento insostenible de la naturaleza, anclada a una idea universal de progreso y desarrollo.

Como actividad agroindustrial, el monocultivo de la caña de dicha gramínea es la demostración de un poder con el que fue posible no solo dominar y transformar la naturaleza, sino subyugar las subjetividades y los órdenes simbólicos de pueblos indígenas, comunidades afrocolombianas y campesinas, que establecieron relaciones de proximidad espiritual con los ecosistemas, posteriormente sometidos a los procesos de transformación de la agricultura extensiva. La plantación de la caña de azúcar es el correlato del colonialismo, externo e interno, en el sentido en que ella misma supone la imposición de una cultura, de un solo modo de entender las relaciones sociedad-naturaleza. De allí que, asociada al monocultivo, subsista una monocultura, caracterizada por estar ancorada originalmente al discurso de la modernidad y a la presencia inequívoca y dominante del "hombre blanco occidental".

Como correlato del colonialismo interno del que habla Boaventura de Sousa Santos, el monocultivo de la caña de azúcar y la monocultura que lo valida y legitima, cumplen la función domadora y denominadora de los diferentes, esto es, de los indios, campesinos y negros ${ }^{33}$, y la acción domesticadora de la naturaleza. Ambas funciones tienen el propósito de mantener, extender en el tiempo y, sobre todo, de naturalizar el colonialismo interno. Y la expresión clara del logro de ese objetivo moderno y modernizante está en la consolidación del discurso del desarrollo, este proclama como camino la explotación y el aprovechamiento de la naturaleza en los únicos términos en los que es posible verla: como proveedora o fuente de recursos (naturales) que deben ser aprovechados al máximo porque así lo demanda la especie dominante; que logró imponerse sobre las otras especies de animales y la naturaleza, en general, gracias a la razón, al conocimiento científico, al triunfo del sentido de la vista y la consecuente sumisión de los otros sentidos, concomitantemente con la subvaloración y la eliminación de los relatos orales y los órdenes simbólicos de aquellos pueblos y comunidades cuyas racionalidades quedaron sepultadas bajo el poder intimidante del discurso, esto es, de la escritura, del poder de la gramática, de la visión académica y científica y de otros dispositivos usados por quienes agenciaron y agencian aún la monocultura.

La dificultad de imaginar la alternativa al colonialismo reside en que el colonialismo interno no es solo ni principalmente una política de Estado,

\footnotetext{
${ }^{33}$ No se hace referencia a comunidades afros e indígenas por cuanto las representaciones sociales que en torno a dichas identidades se propone desde la monocultura, al devenir negativas, se acercan más, en términos de comprensión socio política, a las nomenclaturas de negros e indios.
} 
como sucedía durante el colonialismo de ocupación extranjera; es una gramática social muy vasta que atraviesa la sociabilidad, el espacio público y el espacio privado, la cultura, las mentalidades y las subjetividades. Es, en resumen, un modo de vivir y convivir muchas veces compartido por quienes se benefician de él y por los que lo sufren. [...] La dominación de clase y la dominación étnico-racial se alimentan mutuamente, por tanto, la lucha por la igualdad no puede estar separada de la lucha por el reconocimiento de la diferencia (de Sousa, 2013, p. 24).

En el marco de la llamada Sociología de las ausencias, Boaventura de Sousa Santos distingue cinco modos de producción de ausencia o no existencia. Y habla, a su vez, de cuatro lógicas desde las cuales se produce y se reproduce el colonialismo interno: la primera, la monocultura del saber y del rigor del saber; la segunda, se basa en la monocultura del tiempo lineal; la tercera es la lógica de la clasificación social; la cuarta es llamada la lógica de la escala dominante y la quinta, la productivista.

Aunque las cuatro lógicas propuestas y los cinco modos de producción de ausencia o no existencia de todo aquello que devenga distinto al triunfo de la modernidad europea y del capitalismo guardan relación con la plantación de la caña de azúcar, en tanto expresión de la monocultura consolidada en tiempo y espacio, para efectos de este artículo, se acogen las lógicas tres y cinco. La tres, la lógica de la clasificación social,

[...] se asienta en la monocultura de la naturalización de las diferencias. Consiste en la distribución de las poblaciones por categorías que naturalizan jerarquías. [...] De acuerdo con esta lógica, la no existencia es producida bajo la forma de una inferioridad insuperable, en tanto que natural. Quien es inferior lo es porque es insuperablemente inferior $y$, por consiguiente, no puede construir una alternativa creíble frente a quien es superior". Entre tanto, la 5, la lógica productivista, que se asienta en la monocultura de los criterios de productividad capitalista. En los términos de esa lógica, el crecimiento económico es un objetivo racional incuestionable [...] (de Sousa, 2013, pp. 24-25).

La modernidad europea como proyecto civilizador impuso dentro de sus lógicas discursivas y prácticas, consolidadas dicotomías que sirvieron a los propósitos misionales de sus agenciadores para excluir todo aquello que no encajara, que se tornara "inclasificable" o que confrontara las certezas de un ordenamiento simbólico que logró imponerse apelando a todas las formas de lucha que incluyeron, por supuesto, la catequización, la conversión y la sujeción cognitiva. De allí que "[...] conocimientos populares, laicos, plebeyos, campesinos o indígenas [...] Desaparecen como conocimientos relevantes o conmensurables porque se encuentran más allá de la verdad y de la falsedad. [Al final, las] creencias, opiniones, magia, idolatría, comprensiones intuitivas o subjetivas [...]" (de Sousa, 
2013, p. 33) quedan fuera o terminan subvaloradas por el fuerte agenciamiento del pensamiento racional y científico y la monocultura. Como parte del proceso comunicativo que inició con la llegada de los españoles a América y de la instalación y consolidación del proyecto euro moderno, es claro que arrastramos una historia de des-conocimiento del Otro en su dimensión subjetiva y de su conocimiento y órdenes simbólicos desde los cuales se explicaban el mundo y su propia realidad.

Con la especialización agrícola en el valle geográfico del río Cauca, a través de la presencia hegemónica del monocultivo de la caña de azúcar, se logró consolidar un tipo de pensamiento racional no estético que, contaminado del principio moderno que ve a la naturaleza como una fuente inagotable de recursos (principio de la utilidad máxima), aupó y legitimó toda suerte de acciones transformadoras y domesticadoras de valiosos y estratégicos ecosistemas. Acciones sostenidas no solo en el señalado principio, sino ancoradas con fortaleza a dos realidades culturales ontológicamente atadas al perfil de la élite empresarial: de un lado, la "inconsciencia sistémica" ${ }^{34}$ y, del otro lado, la "ecosistémica" ${ }^{35}$ que bien podría explicar no solo el sentido de las transformaciones naturales, sino los riesgos en los que hoy sobrevive el ser humano como especie ante los efectos que ya viene dejando el cambio climático.

\section{A manera de conclusión}

Si bien a lo largo de este artículo se van dejando pistas claras sobre propuestas categoriales, sus usos y aplicabilidad, y de manera concomitante se entregan elementos conclusivos, es importante insistir en una enorme tarea: asumir el monocultivo de la caña de azúcar como una realidad socio ambiental, fruto de la confrontación entre unas estética-ética diametralmente diferentes y contrapuestas. Y reconocer que el triunfo de una particular estética-ética obedece a la consolidación de un proyecto de sociedad y de Estado que exhibe en su interior complejos procesos comunicativos y ejercicios representacionales que terminaron minimizando a unos otros que, al igual que a la Naturaleza, fueron vistos como obstáculos y enemigos a vencer por parte de quienes quedaron atrapados en las consignas y anhelos del desarrollo científico-técnico. De esa forma, la llegada, instalación, naturalización y expansión del monocultivo de la

\footnotetext{
${ }^{34}$ Asociada a la incapacidad generalizada de los seres humanos para establecer conexiones y reconocer aristas claves, en aras de comprender hechos y fenómenos. Esta categoría se propone con un carácter universal con el que es posible comprender los problemas y las dificultades que afrontan ciudadanos y sociedades para entender situaciones de manera sistémica.

${ }^{35}$ Asociada a la incapacidad generalizada de los seres humanos para entender y asumir el planeta como un macro ecosistema y que, como tal, se compone de una serie de ecosistemas que dan cuenta de una funcionalidad y de unas condiciones de equilibrio (por lo menos, una tendencia al equilibrio homeostático) que, al ser alteradas, afectan el funcionamiento del gran sistema llamado planeta Tierra.
} 
caña de azúcar consolidó una unívoca estética-ética moderna y modernizante con la que se eliminaron, debilitaron o proscribieron otras estética-ética con las que quizás hubiera sido posible establecer diferentes ejercicios representacionales y comunicativos en el marco de unas relaciones con la Naturaleza no ancladas a la dicotomía sociedad-naturaleza.

Para leer, analizar e interpretar los efectos ético-estéticos del monocultivo de la caña de azúcar hay que entender que entre el lenguaje y la ética-estética subsiste una relación compleja. Lo anterior, en la medida en que, para la ética supone la exposición de un deber ser virtuoso, al que es prácticamente difícil llegar con el actual modelo de desarrollo y, para la estética supone la yuxtaposición de una única forma de valorar, gozar, intimar, representar, emocionar y asumir el mundo y sus fenómenos, ancorada al proyecto moderno. Dicha relación está mediada por disputas ideológicas atadas, ética y políticamente, al proyecto civilizador moderno, con todo y su poder avasallante de las maneras y formas estéticaséticas-comunicativas desde las cuales comunidades ancestrales, calificadas como premodernas o incivilizadas, establecieron relaciones íntimas con territorios y con ecosistemas naturales-históricos sobre los que se impuso, no solo un modelo de desarrollo exógeno, sino un tipo particular de valoración estética de lo natural. Justo allí, desde esa particular valoración estética-ética de entornos naturales, ecosistemas o de ese conjunto complejo de relaciones y conexiones ecológicas que llamamos naturaleza, lo que se sobrevino sobre esos territorios fue un fuerte y sostenido proceso de transformación y sometimiento territorial cuyo resultado final, a manera de triunfo antropocéntrico, fue la agroindustria y el monocultivo como modelos, expresiones y símbolos de la producción y reproducción del capital.

De allí que, como experiencia agrícola y ejercicio de poder sobre la naturaleza y sobre culturas representadas como no modernas, el monocultivo exhala vientos antropocéntricos. Desde el sentido del olfato, el monocultivo, en general, y en particular el de la caña de azúcar, huele a poder, en conexión directa con la vista, que de inmediato amplía la dimensión de ese poder constatado cuando al alzar la mirada sobre el valle geográfico del río Cauca, se aprecia el dominio territorial de la plantación de la gramínea y del orden cultural que soporta el monocultivo. Este último, estéticamente, tiene una fuerza hipnotizante en la medida en que su presencia exhala el espíritu, el poder y la experiencia estética de quienes tomaron la decisión ética, económica, ambiental y política, de copar un territorio, anular las territorialidades previamente presentes, anular las conexiones ecosistémicas, reproducir el capital y, con este, las relaciones de poder. El monocultivo de esta gramínea, éticamente, exhibe un deber ser que, desde la racionalidad técnicocientífica, invalida a esos otros seres vivos no humanos y a los elementos no vivos del entorno físico, lo que impide que el ser humano alcance niveles de excelencia que minimicen los riesgos de vivir juntos. 
Lo que se advierte en ese proceso histórico de sometimiento y transformación de la naturaleza es una enconada lucha ideológica que, trasladada al medio natural, dio vida a una de las más complejas dicotomías modernas: preservar/ explotar o conservar/explotar. Se reconocen en esas reducciones mentales dos posibles formas de estar en el mundo, dos vías que permiten el tránsito de unas estéticas-éticas, esto es, de ejercicios valorativos, relaciones íntimas y significativas emocionalidades, que dan cuenta de igual número de órdenes simbólicos desde donde se emprendieron ejercicios comunicacionales con la naturaleza, enmarcados en contextos atravesados por el poder.

El lenguaje, como facultad humana, obedece a un proceso de humanización y de consolidación simbólica de lo humano, con el cual no solo fue posible nombrar el mundo, sino darle sentido de universalidad a los procesos de ocupación de unos territorios o de unas tierras, en las lógicas de los agentes del poder dominante, que se convirtieron en cunas de humanización, civilización y (des)legitimación simbólica de órdenes simbólicos contrapuestos.

Termino estas disquisiciones con las ideas de Augusto Ángel Maya, plasmadas en su obra El retorno de ĺcaro, en el sentido en que si algo caracteriza al ser humano moderno es que estéticamente no estableció una relación de inmanencia con la naturaleza. A través del discurso, elevó los "accidentes geográficos" y las condiciones climáticas "naturales", a la imagen de obstáculos que debían ser vencidos a través de la razón, la ciencia, la técnica y la tecnología.

Pero no basta con comprender el mundo. Hay que sentirlo. Un capítulo fundamental en cualquier filosofía debe ser la estética. Hegel comprendió acertadamente que una de las trampas de la cultura es la castración del "goce". No será posible rescatar la naturaleza, mientras no aprendamos a vibrar con ella (Ángel Maya, 2001, p. 36).

Quizás la invitación que hace Ángel Maya obligue a retomar a Fals Borda y al propio profesor Alfredo Correa de Adréis cuando hablaron de seres sentipensantes. Este concepto, salido de las entrañas y de los diálogos sostenidos por el sociólogo de la IAP con pescadores sucreños, es en sí mismo una provocación ética-estética e incluso poética para hacer y establecer nuevos ejercicios representacionales en el marco de unas relaciones Sociedad-Naturaleza que devienen contaminadas por relaciones de poder y de dominación que de muchas maneras impiden que se den procesos comunicativos en condiciones de simetría.

\section{Referencias}

Ángel Maya, A. (1991). La amenaza contra el tejido de la vida. Cuadernos de geografía, 3(1), 11-19. 
Ángel Maya, A. (2001). El retorno de Ícaro. Cali: CUAO.

Ángel Maya, A. (2009). La Diosa Némesis. Cali: Universidad Autónoma de Occidente.

Arias, M. (2018). Antropoceno. La política en la era humana. Barcelona: Taurus.

Ayala, G. (2006). Representaciones, poder y democracia en Colombia: un asunto comunicativo. En Pensar la comunicación, reflexiones y avances en investigación. Medellín: Universidad de Medellín.

Castro-Gómez, S. (2000). Ciencias sociales, violencia epistémica y el problema de la "invención del otro". Buenos Aires: CLACSO.

Folch, R. (1998). Ambiente, emoción y ética, actitudes ante la cultura de la sostenibilidad. Barcelona: Ariel.

Francisco (24 de mayo de 2015). Laudato Si': Sobre el cuidado de la casa común. Ciudad del Vaticano: Librería Editora Vaticana.

García, R. (1994). Interdisciplinariedad y sistemas complejos. En E. Leff (comp.), Ciencias sociales y formación ambiental (pp. 85-124). Barcelona: Gedisa.

Gamboa, S. (2014). Posibilidades de formación de una cultura tecnológica en la perspectiva de G. Simondon. En A. Camargo (ed.), Educación y Tecnologías de la Información y la Comunicación (pp. 251-272). Bogotá: Universidad Pedagógica Nacional y Doctorado Interinstitucional en Educación.

Gnecco, C. (2008). Discursos sobre el otro: Pasos hacia una arqueología de la alteridad étnica. Revista CS, (2), 101-129.

Kant, I. (2013). Crítica del juicio. Barcelona: Austral.

Latour, B. (2001). La esperanza de Pandora, ensayos sobre la realidad de los estudios de la ciencia. Barcelona: Gedisa.

Mandoki, K. (2006). Estética y comunicación: de acción, pasión y seducción. Bogotá: Editorial Norma.

Morin, E. y Cyrulnick, B. (2005). Diálogos sobre la naturaleza humana. Buenos Aires: Paidós.

Morin, E. (2011). Introducción al pensamiento complejo. Barcelona: Gedisa. 
Noguera, A. P. (2004). El reencantamiento del mundo. Manizales: Universidad Nacional de Colombia IDEA.

Noguera, A. P. (2018). Pensamiento ambiental en la era planetaria Biopoder, bioética y biodiversidad. Una interpretación de los desafíos simbólico-bióticos en la aldea global. Manizales: Universidad Nacional de Colombia.

Polo, M. (2005). Los grandes problemas de la ética ecológica. Solar, 1(1), 29-45. Recuperado de http://revistasolar.org/numero-10-1/

De Sousa, B. (2013). Descolonizar el saber, reinventar el poder. Montevideo: Ediciones Trilce.

Tagliavini, D. y Sabbatella, I. (2011). Marxismo ecológico: elementos fundamentales para la crítica de la economía-política-ecológica. Recuperado de http:// www.mientrastanto.org/boletin-102/ensayo/marxismo-ecologico-elementosfundamentales-para-la-critica-de-la-economia-politic 